\title{
Modification of oil palm empty fruit bunch and sugarcane bagasse biomass as potential reinforcement for composites panel and thermal insulation materials
}

\begin{abstract}
This paper focuses on the study of the effect of modification of Oil Palm Empty Fruit Bunch (OPEFB) and sugarcane bagasse (SCB) biomass as potential reinforcement for composites panel and thermal insulation. Both fibres $\mathrm{H}_{2} \mathrm{O}_{2}$ and $4 \% \mathrm{H}_{2} \mathrm{O}_{2}-2 \%$ silane for $3 \mathrm{~h}$. The influence of modified fibres content in composites was examined by structural changes using image analyser, Fourier transform infrared (FTIR), Scanning Electron Microscopy (SEM), tensile, interfacial shear strength (IFSS) and thermal characteristic. The diameter of both fibres was reduced after treatment and showed decreasing of lignin and hemicellulose in fibre. Tensile strength has been increased by $2 \%$ silane treatment for both fibres and $4 \% \mathrm{H}_{2} \mathrm{O}_{2}$ treatment displays higher result for IFSS. Thermal properties of treated SCB fibre with silane display higher residual content and better thermal stability. SEM characterization showed that $2 \%$ silane treatment removed silica bodies of OPEFB fibre while $4 \% \mathrm{H} 2 \mathrm{O} 2$ treatment uniformly filled porosity of SCB fibre. Finally, results revealed that treated OPEFB fibre is enough to improve compatibility and mechanical properties, while treated SCB fibre was effective in thermal stability for fabrication of composite materials.
\end{abstract}

Keyword: Oil palm empty fruit bunch; Sugarcane bagasse; Fibre treatment; Tensile properties; Thermal properties; Interfacial shear strength 